\title{
Hydrophobicity of Highly Ordered Nanorod Polycrystalline Nickel and Silver Surfaces
}

\author{
Jan Macko1, Natália Podrojková1, Radim Hrdý ${ }^{2,3}$, Andrej Oriňak ${ }^{1^{*}}$, Renáta Oriňaková1, \\ Jaromír Hubálek ${ }^{2,3}$, Jaroslav Vojtuš ${ }^{4}$ Zuzana Kosteckás ${ }^{5}$ Roger M. Smith ${ }^{6}$
}

${ }^{1}$ Department of Physical Chemistry, University of P. J. Šafárik in Košice, Košice, Slovakia

${ }^{2}$ Depatrment of Microelectronics, Brno University of Technology, Brno, Czech Republic

${ }^{3}$ Central European Institute of Technology, Brno University of Technology, Brno, Czech Republic

${ }^{4}$ Department of Architectural Engineering, Institute of Architectural Engineering, Košice, Slovakia

${ }^{5}$ University of Veterinary Medicine and Pharmacy, Košice, Slovakia

${ }^{6}$ Department of Chemistry, Loughborough University, Loughborough, UK

Email: ^andrej.orinak@upjs.sk

How to cite this paper: Macko, J., Podrojková, N., Hrdý, R., Oriňak, A., Oriňaková, R., Hubálek, J., Vojtuš, J., Kostecká, Z. and Smith, R.M. (2019) Hydrophobicity of Highly Ordered Nanorod Polycrystalline Nickel and Silver Surfaces. Journal of Minerals and Materials Characterization and Engineering, 7, 279-293.

https://doi.org/10.4236/jmmce.2019.75020

Received: April 11, 2019

Accepted: September 14, 2019

Published: September 17, 2019

Copyright $\odot 2019$ by author(s) and Scientific Research Publishing Inc. This work is licensed under the Creative Commons Attribution International License (CC BY 4.0).

http://creativecommons.org/licenses/by/4.0/

\begin{abstract}
Highly ordered nickel and silver nanorods arrays prepared by alumina template assisted electrodeposition were investigated to determine the effect of the array geometry on metal surface hydrophobicity and adhesion forces. The nanorod geometry, clustering and pinning were used to characterize surface hydrophobicity and its modulation. A contribution of metal crystallographic orientation to the surface energy was calculated. To characterize nanorod array surface properties and elucidate the source of the particle adhesion effects has been calculated. The dispersive components of surface tension $\gamma_{S}^{D}$ and surface polarizability $k_{\mathcal{S}}$ as surface features that markedly characterize hydrophobicity and adhesion, were calculated. The highest hydrophobicity was found for $\mathrm{Ag}$ nanorods with aspect ratio of 10 then $\mathrm{Ni}$ nanorods with aspect ratio 10 . The same geometry of nanorods particles resulted in different surface hydrophobicity and it was ascribed to the orientation of Ag and Ni crystals formed on the top of nanorods. Due to high hydrophobicity nanorod array surfaces could be used as an antifouling surface in medicine to select areas on implant surface not to be colonized by cells and tissues.
\end{abstract}

\section{Keywords}

Nanorods, Silver, Nickel, Hydrophobicity, Surface Energy, Crystallinity

\section{Introduction}

Surface properties such as morphology are stable features of the surface, compared to chemical modifications which degrade over time [1]. For hydrophobic 
surfaces there are two basic approaches that can be considered to increase surface hydrophobicity: a) decreasing the surface energy by modifying the surface chemistry and b) decreasing the surface energy by increasing the surface roughness to increase the effective surface area, which can be expressed by the apparent contact angle $\theta_{\text {rough }}(1)$ [2]:

$$
\cos \theta_{\text {rough }}=r \cos \theta_{\text {flat }}
$$

where $r$ is the roughness factor defined as ratio of the actual surface area to its horizontal projection for Wenzel model. For the alternative Cassie-Baxter model the apparent contact angle is described by (2) [2].

$$
\cos \theta_{\text {rough }}=f_{s}\left(\cos \theta_{\text {flat }}+1\right)-1
$$

where $f_{s}$ is the fraction of the solid surface in contact with the water droplet and is always less than one. A decrease of $f_{s}$ resulted in an increase of $\theta_{\text {rough }}$, and gradually leads to a hydrophobic or superhydrophobic surface.

One method of increasing hydrophobicity of a surface by increasing the effective area is to coat it with a layer of nanorods. Considering nanorods as having a cylindrical shape as shown in Figure 1, the following two equations for $r$ and $f_{s}$ values have been obtained [2].

$$
r=\frac{s+n\left(2 \pi \rho H_{r}\right)}{s}=1+\frac{n\left(2 \pi \rho H_{r}\right)}{s}
$$

and

$$
f_{s}=\frac{n\left(\pi \rho^{2}\right)}{s}
$$

where $\rho$ is radius of the cylinder, $H_{r}$ is cylinder height and $s$ is the two dimensional surface area that the nanorods have grown on and $n$ is number of nanorods in area $s$ [2]. Hence, two equations have been derived describing Wenzel $\left(\theta_{W}\right)(5)$ and Cassie-Baxter $\left(\theta_{C B}\right)(6)$ angles as a function of nanorod geometry [2]:

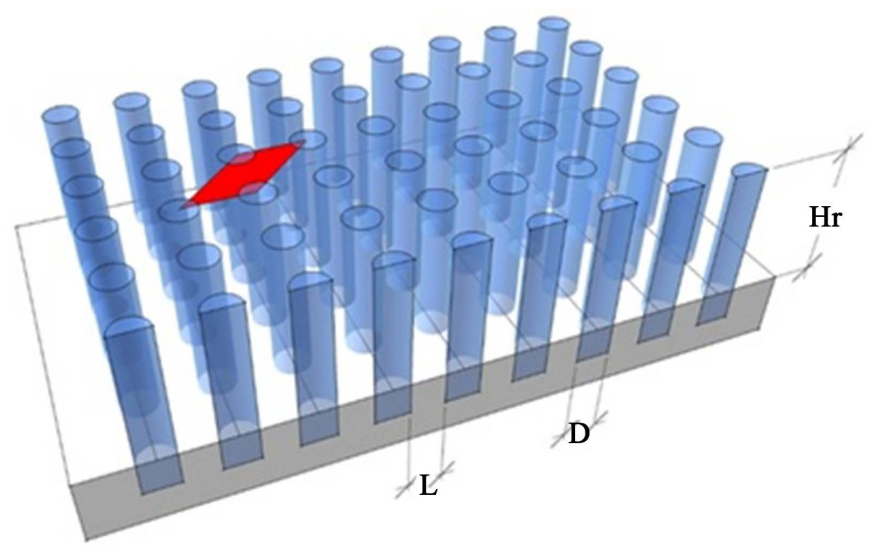

Figure 1. Schematic drawing of cylindrical nanorods arrays with geometry characteristics: nanorod diameter D, nanorod spacing L, nanorod height Hr. Red rhomboid indicates hexagonal orientation of nanorods in template. 


$$
\begin{aligned}
& \theta_{W}=\cos ^{-1}\left[\left(1+\frac{n\left(2 \pi \rho H_{r}\right)}{s}\right) \cos \theta_{y}\right] \\
& \theta_{C B}=\cos ^{-1}\left[\frac{n\left(\pi \rho^{2}\right)}{s}\left(\cos \theta_{y}+1\right)-1\right]
\end{aligned}
$$

The nanorods can be prepared using filler templates. The thin porous anodic alumina oxide (AAO) template derived nanowire/nanopillar arrays are highly-ordered and highly-oriented. They have well-tunable and precisely-controlled structural parameters, including shape, size, interspace, and density, which are all derived from the structural features of the original AAO template [3] [4]. In addition these highly-ordered and highly-oriented nanowire/nanopillar arrays are more promising for many applications because of their uniform functionality [5]. It has been recently demonstrated that a surface formed with metal nanorods, such as copper, may confer a strongly hydrophobic property to the surface, provided the nanorods are allowed to cluster in a particular manner [6]. Self-organization of the nanowires can occur resulting in clustering and made them taller than a critical height resulting in surface strong hydrophobicity [6] [7]. The copper nanowires became progressively hydrophobic with an increase in their length up to $35 \mu \mathrm{m}$ and the maximum contact angle measured was $141^{\circ}$ [6]. As the liquid between the nanorods evaporates, the capillary force generated due to the evaporation pulls the nanorods together to form clusters [7]. This process, so called the "nanocarpet effect" [8], has already been utilized to form cellular networks from carbon nanotubes arrays [9] and as scaffolds for cell culture. It was shown that a good control over the cluster size and shape enables the design of efficient applications [10] [11] [12]. This phenomenon utilizes basic contradictions that underlie adhesive hydrophobicity in the absence of an external hydrophobizing agents. While the air pockets between the nanorod clusters trap air and produce structural hydrophobicity (Cassie-Baxter), the tips of the inherently hydrophilic nanorods stabilize the air pockets by pinning [10] the solid-liquid contact line. The static state of the water droplets on the nanorod surfaces can be either in the Wenzel or Cassie-Baxter state, depending on the rod height and the rod characteristic energy. When the rod height was low, the water droplet was in the Wenzel state. As the rod height increased or the rod characteristic energy decreased, the surface becomes more hydrophobic and changed to the Cassie-Baxter state. The dynamic state of the water droplet can be classified into three groups by its shape, which depends on the rod height, the rod characteristic energy, and the magnitude of the applied force [13]. The water droplet in the last group maintains its original spherical shape. This occurs only when the static droplet is in the Cassie-Baxter state [14].

The polycrystalline nature of $\mathrm{Ag}$ and $\mathrm{Ni}$ nanorods introduces some variation in their morphology, including length, diameter, and shape [15]. Generally, the surface energies of metal surfaces are quite high, thus metal surfaces are regarded as hydrophilic. The geometry, the atomic arrangements, and the chemi- 
cally heterogeneous characteristics of the solid surfaces play key roles in surface wetting behavior. The surface energy also plays an important role in particle growth and shape selection. Surface energies associated with different crystallographic planes are usually different, and the general sequence $\gamma(111)<\gamma(100)<$ $\gamma(110)$ holds for most face-centered cubic crystals, such as the precious metals. The thermodynamically preferable surfaces are those with densely packed planes of atoms exposed, i.e. the low-Miller-index planes (e.g. the familiar (100) and (111) planes of a face centered-cubic lattice. For Ag the close-packed (111) face has the lowest energy, followed by the (100) and (110) faces [13]. The final shape of each Ag or Ni nanoparticle is determined thermodynamically by minimizing the total surface energy and/or kinetically by the growth rate, especially by a ratio of the growth rate along the (100) direction to the growth rate along the (111) direction [16]. Wulff polyhedrons contain extended (111) faces and are therefore often incorporated in the structure of noble metallic particle structures [15]. The hydrophobicity of the $\mathrm{Ni}$ and $\mathrm{Ag}$ surfaces produced by electrochemically controlled deposition has been discussed previously [17] [18] and the surface geometry and crystallographic orientation enabled modulation of surface hydrophobicity.

The aim of the present study was to extend this work and prepare $\mathrm{Ag}$ and $\mathrm{Ni}$ nanorods by electrodeposition and to determine the influence of composition and of nanorod aspect ratio on their surface hydrophobicity. The crystalline structure of the materials will also be examined and compared with earlier studies.

\section{Materials and Methods}

All operations were performed at atmospheric pressure and $25^{\circ} \mathrm{C}$. All chemicals were p.a. grade. Ultrapure water with resistivity of $18.2 \mathrm{M} \Omega \mathrm{m}$ was prepared with Laboratory purification system (MRC, Ltd. UK). Electron micrographs surfaces were measured using a SEM JEOL JSM 7001F, (JEOL, Japan). Images of water drops were taken with EO 3112-C (Edmund Optics, USA) camera and water contact angles were analyzed by software ImageJ with plugin LB-ADSA. The surface area of nanorod top side was measured by using the measure-particles option in Image J. An Autolab PGSTAT 302N, (Metrohm, Netherlands was used to apply current pulses for metal deposition

\subsection{Preparation of Alumina Oxide Membrane Templates}

Nanorod array silicon wafers were obtained from Brno University of Technology and were coated with a $200 \mathrm{~nm}$ tungsten layer and then with a $150 \mathrm{~nm}$ high-purity thin aluminum layer $(99.99+\%)$ by thermal evaporation (PVD). The thin porous AAO templates were prepared as described earlier [19] by a one-step anodic oxidation of aluminium thin film by using a constant voltage of $40 \mathrm{~V}$ in 0.3 $\mathrm{mol} / \mathrm{L}$ oxalic acid solution in a conventional two-electrode system at $16^{\circ} \mathrm{C}$ for 180 s using a flow system controlled by a membrane pump, a power source, a 
thermostat and a controlling computer. A gold wire was used as counter electrode. Vertically aligned pores were formed by the honeycomb structure in the alumina layer. A high current drop indicated that the $\mathrm{Al}$ layer had been completely transformed to $\mathrm{AAO}$ and $\mathrm{WO}_{3}$ nanodots, which were formed on the $\mathrm{W}$ and AAO interface below each pore. The sample was then washed with distilled water and dried.

\subsection{Preparation of the Cylindrical Arrays}

Electrochemical pulse deposition was used to fabricate the silver nanorods onto nanoporous AAO templates, with either 50 or $500 \mathrm{~nm}$ rods. Deposition was performed from $0.2 \mathrm{~mol} / \mathrm{L} \mathrm{AgNO}_{3}(\mathrm{pH} 2.5)$ at $60^{\circ} \mathrm{C}$ in two steps each consisting of 20 deposition pulses with a current intensity of $1 \mathrm{~mA}$ and a duration of $2 \mathrm{~s}$. The electrolyte was forced to circulate on the AAO template surface for $10 \mathrm{mi}$ nutes before the pores of the membrane were filled. The current pulses were applied using an Autolab PGSTAT $302 \mathrm{~N}$ potentiostat with a standard two-electrode setup. A thin gold layer prepared by evaporation on the AAO membrane was used as a cathode and a platinum electrode as an anode. Finally, the surface was etched in aqueous solution containing $5 \mathrm{ml}$ of $85 \% \mathrm{H}_{3} \mathrm{PO}_{4}$ and $3 \mathrm{~g} \mathrm{CrO}_{3}$ for $6 \mathrm{~s}$ at a temperature of $45^{\circ} \mathrm{C}$ to remove the AAO.

Nickel nanorods were prepared by electrochemical deposition in modified Watts bath at $55^{\circ} \mathrm{C}$ composed of $250 \mathrm{~g} / \mathrm{L} \mathrm{NiSO}_{4} \cdot 6 \mathrm{H}_{2} \mathrm{O}, 50 \mathrm{~g} / \mathrm{L} \mathrm{NiCl}{ }_{2} \cdot 6 \mathrm{H}_{2} \mathrm{O}$. The $\mathrm{pH}$ was adjusted with $34 \mathrm{~g} / \mathrm{L} \mathrm{H}_{3} \mathrm{BO}_{3}(\mathrm{pH} 3.8)$ until nanorod growth was observed using the same pulse sequence.

\subsection{Measurement of Contact Angles}

Contact angles were measured by dropping water, glycerol, dimethylformamide (DMF) or dimethylsulfoxide (DMSO) onto the surfaces. The droplets were imaged with an EO-3112C colour USB camera (Edmund Optics, USA) and Image J software with plug-in LB-ADSA were used to determine the contact angles.

\section{Results and Discussion}

\subsection{Results of SEM Nanorods Surface Characterization}

Silver and nickel coated nanorods were prepared by electrodeposition on AAO templates which were then dissolved. Compared with arrays synthesized by other methods, AAO template-directed nanowire/nanorod arrays are highly-ordered and highly-oriented. They have well-tunable and precisely-controlled structural parameters, including shape, height, size, interspace, and density, which are all guided from the structural features of AAO template. It was possible to accommodate the diameter of the nanorods to $50( \pm 2) \mathrm{nm}$ and the height to be 50 $( \pm 3.5) \mathrm{nm}$ or $500 \mathrm{~nm}$ in height, with a corresponding aspect ratios (AR) of 1 or 10 , whilst keeping the spacing of the nanorods constant based on the template structure. SEM micrographs of the top surfaces of the array of silver nanorods (A, B) and nickel nanorods (C, D) (Figure 2) showed that the nanorods were 


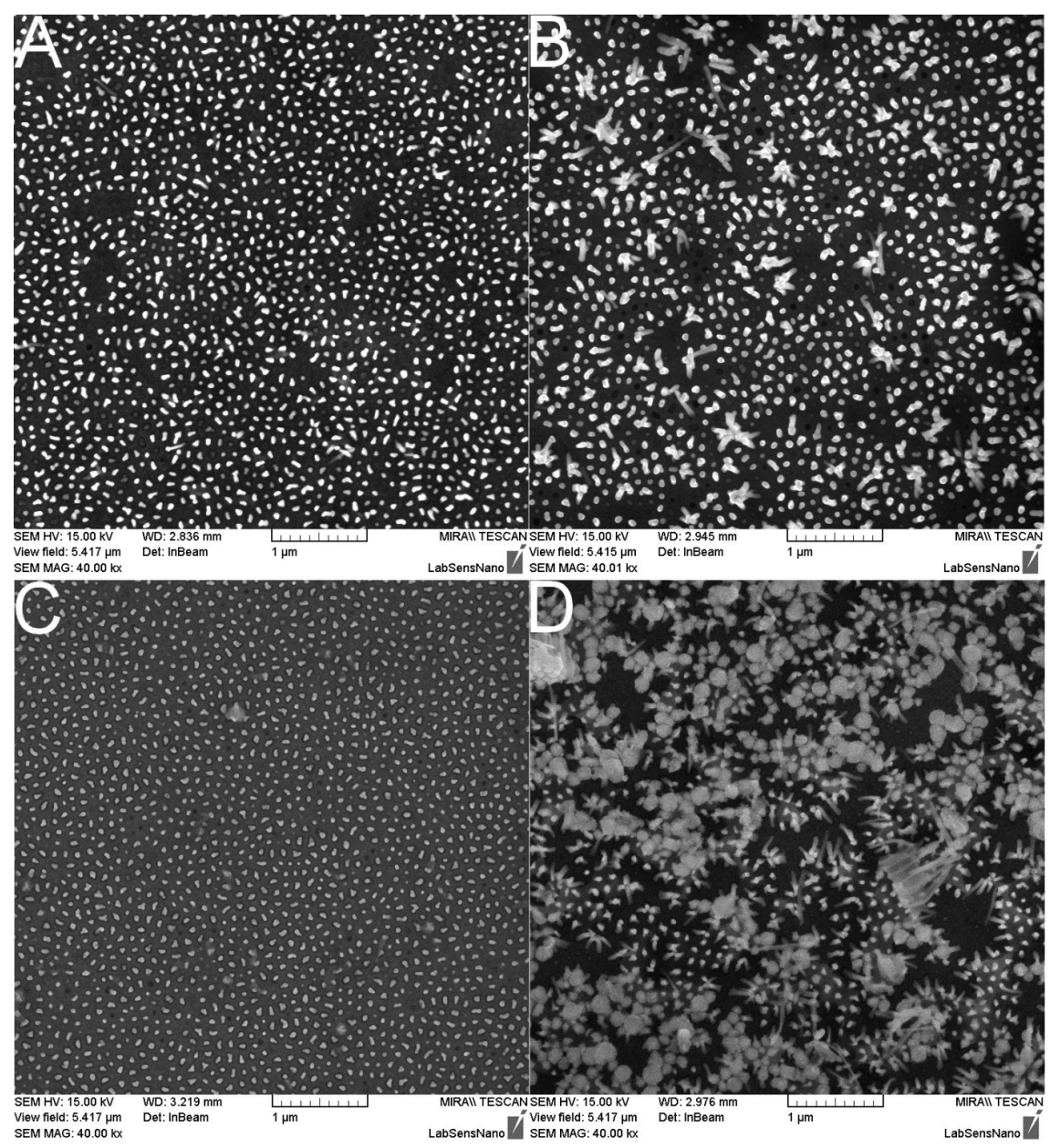

Figure 2. Representative SEM top view micrograph of nanorods array surface prepared. (A) Silver array of $50 \mathrm{~nm}$ nanorods; (B) Silver array of $500 \mathrm{~nm}$ nanorodss; (C) Nickel array of $50 \mathrm{~nm}$ nanorods; (D) Nickel array of $500 \mathrm{~nm}$ nanorods Magnification $40 \mathrm{kx}$, length of scale bar $1 \mu \mathrm{m}$. Clustering and pinning of nanorods with aspect ratio 10 ((B), (D)).

pulled together due to effect of surface tension during drying (most obviously at $500 \mathrm{~nm}$ height). The images of the nanorods also showed that the nanorods were aligned parallel to each other. The average spacing between two adjacent rods was approximately $115 \mathrm{~nm}$ for Ni 50 and Ni 500 and $146 \mathrm{~nm}$ for $\mathrm{Ag} 50$ and $\mathrm{Ag}$ 500 with an average nanorods length of 50 and $500 \mathrm{~nm}$ and an average diameter of $33 \mathrm{~nm}$ for Ni 50 and $\mathrm{Ni} 500$ and $41 \mathrm{~nm}$ for $\mathrm{Ag} 50$ and $\mathrm{Ag}$ 500. The nanorods density was determined to be $81 \mathrm{rods} / \mu \mathrm{m}^{2}$ in case of $\mathrm{Ag} 50$ and Ni 50 and 75 rods $/ \mu \mathrm{m}^{2}$ for $\mathrm{Ag} 500$ and Ni 500 .

\subsection{Results of the Ag and Ni Nanorods Surface Hydrophobicity Measurements}

The surface hydrophobicity of the nickel and silver high ordered nanorods surfaces was determined from the surface contact angles for four solutions (water, glycerol, DMSO, and DMF) (Table 1). 
Table 1. Contact angles of liquids at Ag and Ni nanorod array surfaces with different aspect ratios ( $\mathrm{AR}=$ height/width). (Images of water drops used to contact angle measurement added)

\begin{tabular}{|c|c|c|c|c|c|}
\hline \multicolumn{6}{|c|}{ Contact angle } \\
\hline & water & & glycerol & DMF & DMSO \\
\hline Ag AR 10 & & 150 & 112 & 10 & 10 \\
\hline Ag AR 1 & & 105 & 98 & 10 & 10 \\
\hline Ni AR 10 & & 105 & 110 & 10 & 30 \\
\hline Ni AR 1 & & 97 & 77 & 25 & 30 \\
\hline
\end{tabular}

Using the solvent properties in Table 2 the partial components of the surface tension can be determined from the relationships Equations (8) and (9) [23]. From the graphical relation of $\gamma_{L}^{P} /\left(\gamma_{L}^{D}\right)^{1 / 2}$ vs $(1+\cos \theta) \gamma_{L} /\left(\gamma_{L}^{D}\right)^{1 / 2}$, the dispersive component of the surface tension $\left(\gamma_{S}^{D}\right)$ can be determined. Increasing values of $\gamma_{S}^{D}$ correspond to an increase in the surface hydrophobicity.

$$
\begin{aligned}
& \gamma_{S}^{D}=\left(\frac{\frac{\gamma_{L}}{\gamma_{L}^{D}}(1+\cos \theta)-k_{S} \frac{\gamma_{L}^{P}}{\sqrt{\gamma_{L}^{D}}}}{2}\right)^{2} \\
& \frac{\gamma_{L}}{\sqrt{\gamma_{L}^{D}}}(1+\cos \theta)=2 \sqrt{\gamma_{S}^{D}}+k_{S} \frac{\gamma_{L}^{P}}{\sqrt{\gamma_{L}^{D}}}
\end{aligned}
$$

The values for Ag nanorods with aspect ratio (AR) 10 were higher than those with an aspect ratio 1 (Figure 3 ) with the highest contact angle- $150^{\circ}$ being in the superhydrophobicity region (Figure 4). The results for Ni nanorods (Figure 5) showed the slopes of $\gamma_{s}^{D}$ coefficients for both aspect ratios were very similar. For both metals, the higher surface hydrophobicities were found for nanorods with higher aspect ratio and at the highest value of the dispersive component of the surface tension. The surface energy decreased with increasing AR. This hydrophobicity boosting phenomenon could be explained also by elastocapillary coalescence [24]. High hydrophobicity of prepared nanorod metal array surfaces enhanced by elastocapillary coalescence creates unacceptable environment for cell adhesion and spreading as it is mentioned in our former publication [18]. Hydrophobic silver nanorod array surfaces are supposed to be used as antiadhesive substrates for bacterial cell adhesion for bacterial cell adhesion to prevent bacterial infection spreading. 


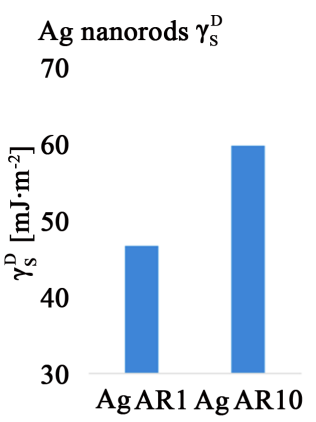

(A)
Ni nanorods $\gamma_{\mathrm{s}}^{\mathrm{D}}$
70

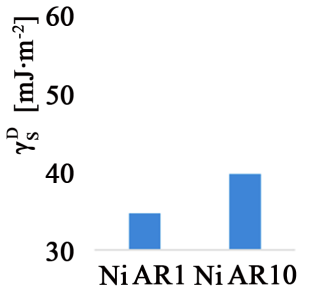

(B)

Figure 3. Trends in the surface tension dispersive components change of $\gamma_{S}^{D}$ of prepared nanorods surfaces; (A) Ag nanorods; (B) Ni nanorods.

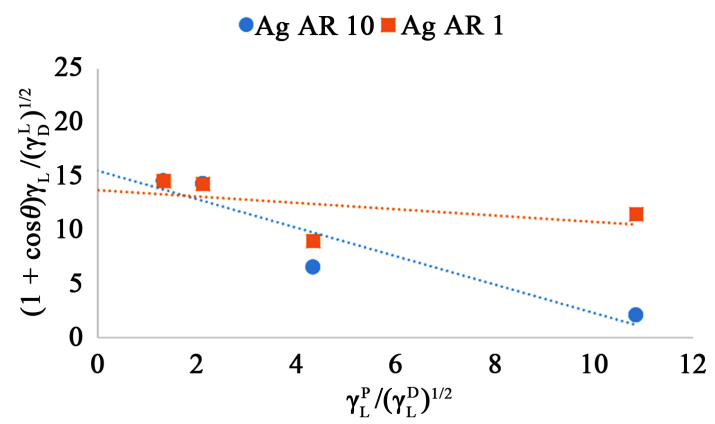

Figure 4. Graphical evaluation of partial surface tension components of the Ag nanorods arrays.

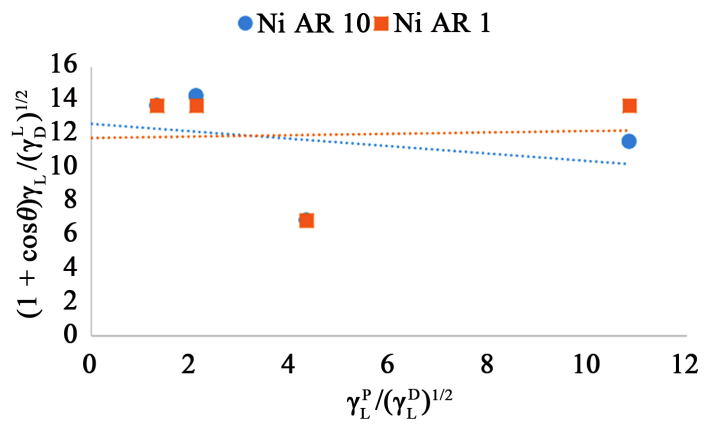

Figure 5. Graphical evaluation of partial surface tension components of the Ni nanorods arrays.

Table 2. Dispersion components of surface tensions of liquids used to determine surface energy $C$-capillary constant, $\gamma$-total liquid surface tension, $\gamma_{L}^{D}$-dispersion component of liquid surface tension, $\gamma_{L}^{P}$-polar component of liquid surface tension [20] [21] $[22]$.

\begin{tabular}{|c|c|c|c|c|}
\hline & $C\left(\mathrm{~m}^{-2}\right)$ & $\gamma\left(\mathrm{mJ} \cdot \mathrm{m}^{-2}\right)$ & $\gamma_{L}^{D} \quad\left(\mathrm{~mJ} \cdot \mathrm{m}^{-2}\right)$ & $\gamma_{L}^{P} \quad\left(\mathrm{~mJ} \cdot \mathrm{m}^{-2}\right)$ \\
\hline Water & $1.3475 \times 10^{5}$ & 72.8 & 21.8 & 51 \\
\hline Glycerol & $1.9274 \times 10^{5}$ & 63.4 & 37 & 26.4 \\
\hline DMSO & $2.45 \times 10^{5}$ & 44 & 36 & 8 \\
\hline DMF & $2.5041 \times 10^{4}$ & 34.4 & 24 & 10.4 \\
\hline
\end{tabular}


The surface polarizability $\left(k_{S}\right)$ can be derived from the regression equation $y=$ $a+x b$, where $b$ represents $k_{S}$ and $\gamma_{S}^{D}$ could be calculated from $a^{2} / 4$ [23]. The calculated surface polarizabilities are shown in Figure 6. The most polar surface is represented by low aspect ratio Ni nanorods with the highest wettability. From the SEM micrographs (Figure 2) the surface was highly ordered.

The experimental contact angles showed a good correlation with calculated values derived from Equations (1)-(4) (Figure 7) for the Wenzel state of hydrophobicity using the parameters in Table 3.

The results for $\gamma_{S}^{D}$, polarizability, adhesion force and contact angle were compared to published values for randomly nanopatterned and highly ordered and oriented $\mathrm{Ni}$ and Ag surfaces [17] [18] and showed that the surface hydrophobicity increased from random patterned to highly ordered and oriented surfaces (Table 4).

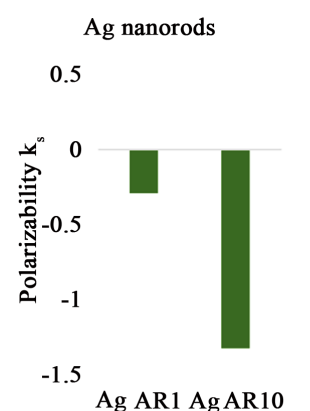

(A)

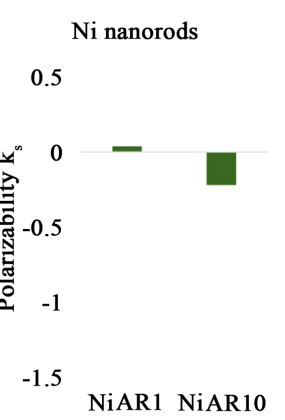

(B)

Figure 6. Trends in the surface polarizability change of $k_{S}$ of prepared nanorods array surfaces.
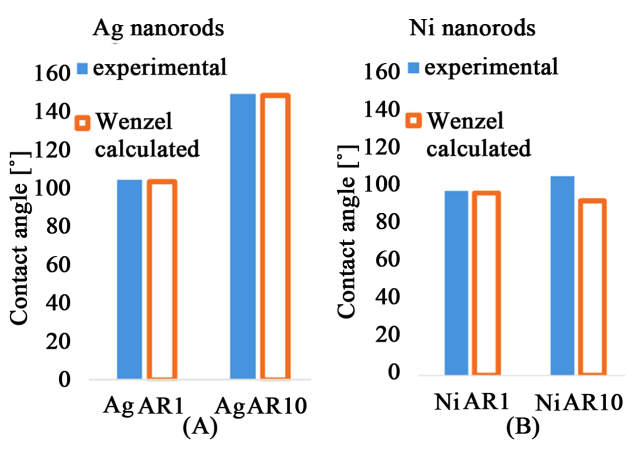

Figure 7. Water contact angles of nanorod arrays prepared. Blue bars-experimentally measured. Orange outlined bars-calculated using Wenzel model.

Table 3. Detailed data for Wenzel state calculation of the surface hydrophobicity of the nanorods.

\begin{tabular}{ccccccccc}
\hline & $\mathrm{S} / \mathrm{mm}^{2}$ & $\Theta /^{\bullet}$ & $\boldsymbol{r}$ & $\boldsymbol{\varphi}_{\boldsymbol{s}}$ & $\boldsymbol{f}_{\boldsymbol{s}}$ & Wenzel & $\begin{array}{c}\text { Adhesion } \\
\text { force/pN }\end{array}$ & $E / \mathrm{TPa}$ \\
\hline Ag AR 1 & 5.59 & 105 & 1.0001 & 0.0000165 & 0.071 & 104 & 69.6 & 776 \\
Ag AR 10 & 1.01 & 150 & 1.001 & 0.0015700 & 0.071 & 149 & 881 & 1005 \\
Ni AR 1 & 6.41 & 97 & 1.0001 & 0.0000107 & 0.075 & 96 & 175 & 1.64 \\
Ni AR 10 & 5.59 & 105 & 1.001 & 0.0000106 & 0.075 & 92 & 48 & 869 \\
\hline
\end{tabular}


Table 4. Summarizing data comparison of random surfaces and highly ordered surfaces of nanorods.

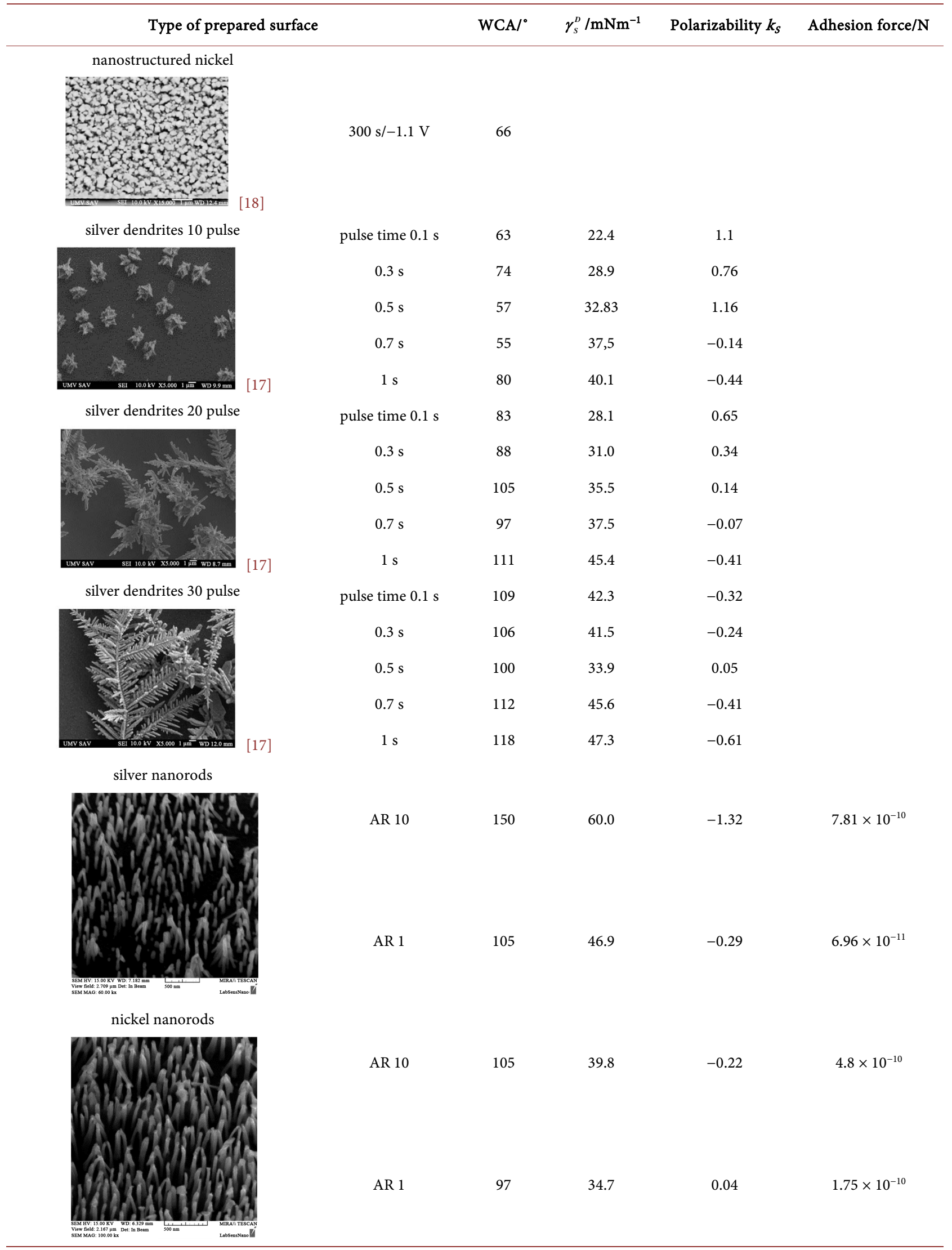




\subsection{Crystallographic Analysis of Highly Ordered Nanorod Surfaces and Ag and Ni surface Energy Calculation}

XRD measurements of the Ag and Ni nanorods confirmed the polycrystalline structure of the surfaces (Figure $8(\mathrm{~A})$ and Figure $8(\mathrm{~B})$ ) and peaks corresponding to (111), (200), (220), (311) and (222) orientation of metallic Ag and (111), (200), (220) of metallic Ni were resolved. These peaks are consistent with the Joint Committee on Powder Diffraction standards (JCPDS 04-0784) and other reports [25]. Furthermore, the preferred orientation along the (111) plane indicates that the grown nanorods can be readily indexed as face centered cubic Ag and $\mathrm{Ni}$, due to sharp peak seen at about $47.5^{\circ}$ (Figure $8(\mathrm{~A})$ ). It may be noted that other Bragg reflections were comparatively weak and considerably broadened relative to the (111) reflection, which indicates that $\mathrm{Ag}$ and $\mathrm{Ni}$ nanorods are anisotropic in shape.

The surface energy of the polycrystalline $\mathrm{Ni}$ and Ag nanorods was calculated based on crystallographic data with software VESTA (Figure 9).

Wulff projection has been applied and surface energy has been calculated in accordance with Equation (9) [26] and showed that Ag nanopillars have smaller surface energy and higher hydrophobicity than nanopillars of $\mathrm{Ni}$ which was more hydrophilic (Table 5).

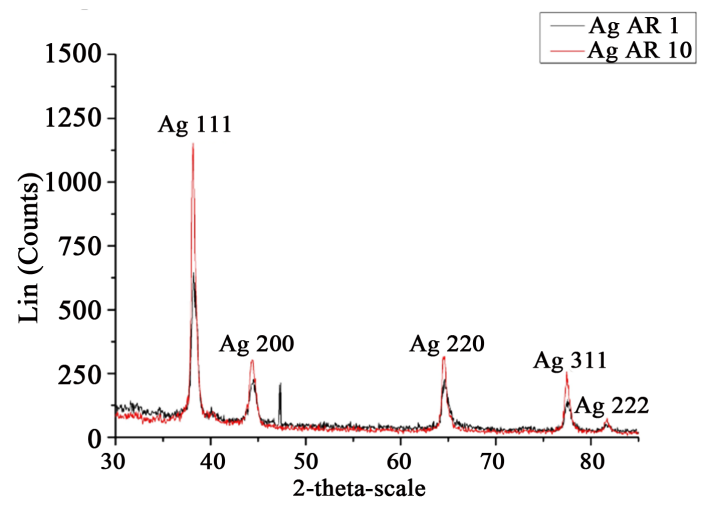

(A)

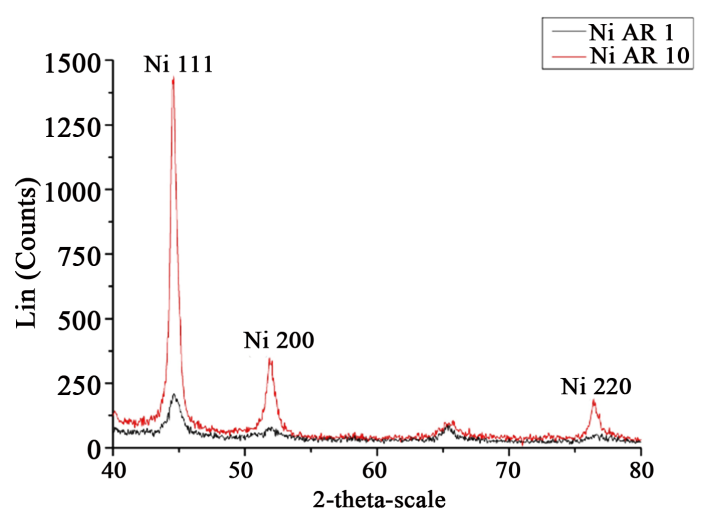

(B)

Figure 8. Crystalographic profile of prepared nanorods array surfaces. (A) Ag nanorods; (B) Ni nanorods. 


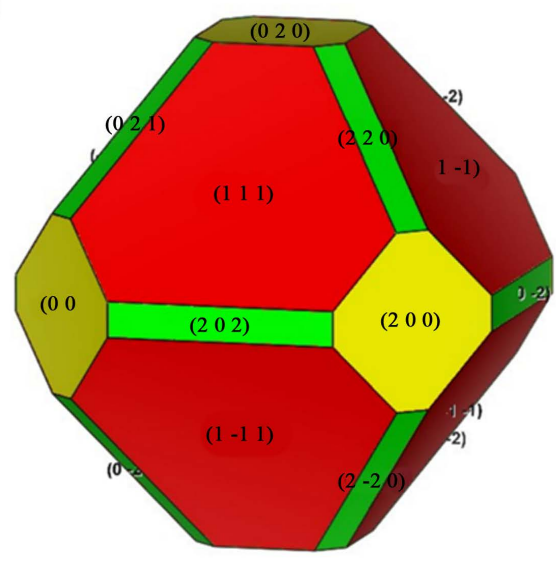

(A)

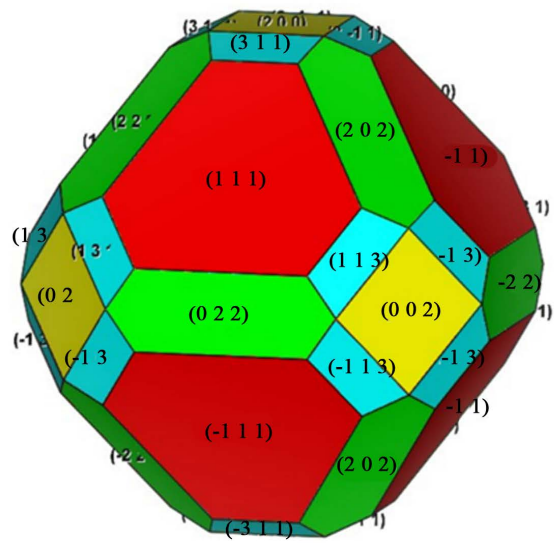

(D)

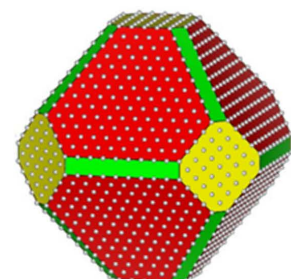

(B)

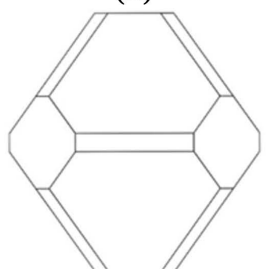

(C)

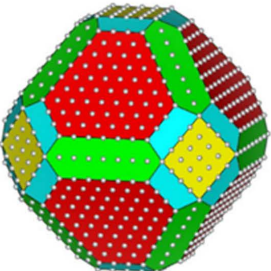

(E)

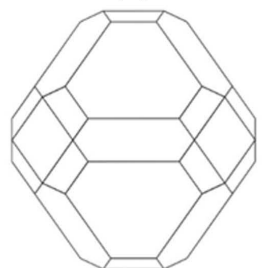

(F)

Figure 9. Crystal models reconstructed from obtained crystallographic data. A-Crystal of nickel; B-Crystal of nickel with atom distribution; C-Wulf projection of nickel crystal; D-Crystal of silver; E-Crystal of silver with atom distribution; F-Wulf projection of silver crystal.

Table 5. Calculated surface energies based on crystallographic data.

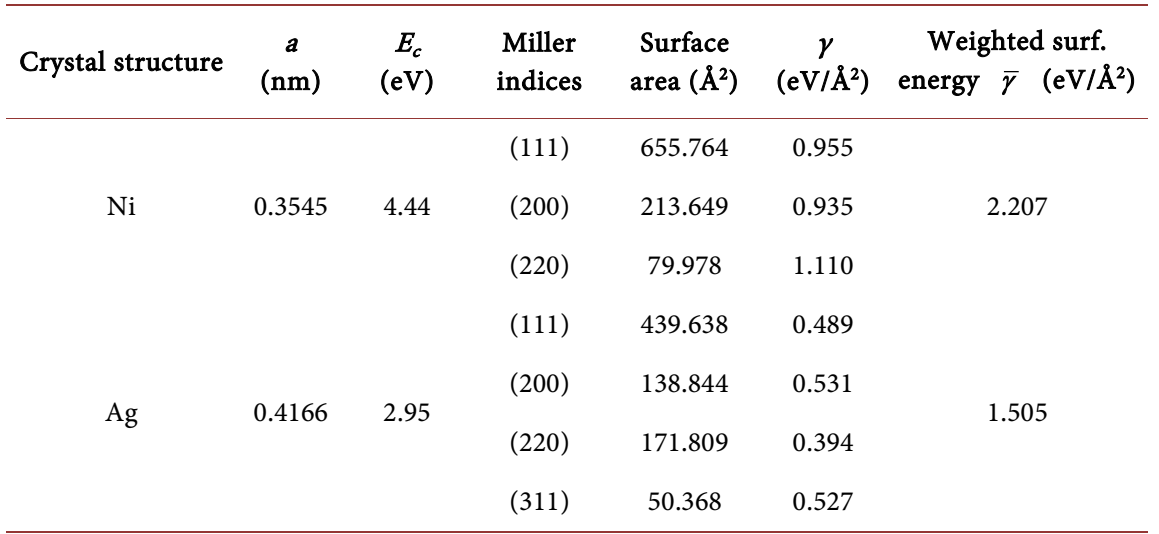

$$
\bar{\gamma}=\frac{\sum_{\{h k l\}} \gamma_{h k l} A_{h k l}}{\sum A_{h k l}}
$$


where:

$\gamma_{h k l}$ - surface tension for selected plane.

$A_{h k l}$-area of selected surface plane.

\section{Conclusions}

Highly ordered, well-aligned, Ni and Ag nanorod arrays could be prepared by templated electrochemical deposition and retain nanometer-scale features from the template. Wetting data showed that the most hydrophobic material was Ag surface with aspect ratio 10 and a polycrystalline structure with dominant face orientation (111). The surface hydrophobicity increased from Ni AR 1 to Ag AR 10 where the contact angle about $150^{\circ}$ was measured. Ni nanorod surfaces had lower hydrophobicity and nanorods with a low aspect ratio had a reduced wetting. Thus surface energy decreased with an increase in planar density.

The combination of nanoscale surface geometry and crystallographic plane orientation features could provide important surfaces with modulated hydrophobicity, repellent effects to cells adhesion, and antimicrobial functions as well as self-cleaning processes. In further studies the authors plan to investigate molecular-based surface hydrophobicity and the impact of water molecule orientation.

\section{Acknowledgements}

This research has been financially supported by grant MŠ SR VEGA 1/0074/17, APVV-16-0029.

\section{Conflicts of Interest}

The authors declare no conflicts of interest regarding the publication of this paper.

\section{References}

[1] Lee, J., Kang, B.S., Hicks, B., Chancellor, T.F., Chu, B.H., Wang, H.T., Keselowsky, B.G., Ren, F. and Lele, T.P. (2008) The Control of Cell Adhesion and Viability by Zinc Oxide Nanorods. Biomaterials, 29, 3743-3749. https://doi.org/10.1016/j.biomaterials.2008.05.029

[2] Bayat, A., Ebrahimi, M. and Moshfegh, A.Z. (2014) Correlation between Surface Roughness and Hydrophobicity of GLAD RF Sputtered PTFE/W/Glass Nanorod Thin Films. Vacuum, 101, 279-282. https://doi.org/10.1016/j.vacuum.2013.09.007

[3] Masuda, H. and Fukuda, K. (1995) Ordered Metal Nanohole Arrays Made by a Two-Step Replication of Honeycomb Structures of Anodic Alumina. Science, 268, 1466-1468. https://doi.org/10.1126/science.268.5216.1466

[4] Resende, P.M. and Martín-González, M. (2019) Sub-10 nm Porous Alumina Templates to Produce Sub-10 nm Nanowires. Microporous and Mesoporous Materials, 284, 198-204. https://doi.org/10.1016/j.micromeso.2019.04.020

[5] Ayyub, P. (2009) Aligned Nanorod Arrays: Additive and Emergent Properties. Journal of Cluster Science, 20, 429-451. https://doi.org/10.1007/s10876-009-0254-5

[6] Bhattacharya, P., Gohil, S., Mazher, J., Ghosh, S. and Ayyub, P. (2008) Universal, 
Geometry-Driven Hydrophobic Behaviour of Bare Metal Nanowire Clusters. Nanotechnology, 19, Article ID: 075709. https://doi.org/10.1088/0957-4484/19/7/075709

[7] Chakraborty, I., Singh, N., Gohil, S., Ghosh, S. and Ayyub, P. (2013) Clustered Copper Nanorod Arrays: A New Class of Adhesive Hydrophobic Materials. Soft Matter, 9, 11513-11520. https://doi.org/10.1039/c3sm52243a

[8] Fan, J.G., Dyer, D., Zhang, G. and Zhao, Y.P. (2004) Nanocarpet Effect: Pattern Formation during the Wetting of Vertically Aligned Nanorod Arrays. Nano Letters, 4, 2133-2138. https://doi.org/10.1021/nl048776b

[9] Correa-Duarte, M.A., Wagner, N., Rojas-Chapana, J., Morsczeck, C., Thie, M. and Giesig, M. (2004) Fabrication and Biocompatibilut of Carbon Nanobute-Based 3D Networks as Scaffolds for Cell Seeding and Growth. Nano Letters, 4, 2233-2236. https://doi.org/10.1017/CBO9781107415324.004

[10] Chakraborty, I. and Ayyub, P. (2012) Controlled Clustering in Metal Nanorod Arrays Leads to Strongly Enhanced Field Emission Characteristics. Nanotechnology, 23, 15704-15707. https://doi.org/10.1088/0957-4484/23/1/015704

[11] Pal, A., Gohil, S., Ghosh, S. and Ayyub, P. (2012) Polarization Selection Rules for Surface-Enhanced Raman Scattering from Anisotropic Microstructured Surfaces. Journal of Physical Chemistry C, 116, 18504-18507. https://doi.org/10.1021/jp305136r

[12] Mondal, S., Chakraborty, I., Ahmad, S., Carvalho, D., Singh, P., Lad, A.D., Narayanan, V., Ayyub, P., Kumar, G.R., Zheng, J. and Sheng, Z.M. (2011) Highly Enhanced Hard X-Ray Emission from Oriented Metal Nanorod Arrays Excited by Intense Femtosecond Laser Pulses. Physical Review B: Condensed Matter and Materials Physics, 83, Article ID: 035408. https://doi.org/10.1103/PhysRevB.83.035408

[13] Foiles, S.M., Baskes, M.I. and Daw, M.S. (1986) Embedded-Atom-Method Functions for the Fcc Metals Cu, Ag, Au, Ni, Pd, Pt, and Their Alloys. Physical Review B, 33, 7983-7991. https://doi.org/10.1103/PhysRevB.33.7983

[14] Barbic, M., Mock, J.J., Smith, D.R. and Schultz, S. (2002) Single Crystal Silver Nanowires Prepared by the Metal Amplification Method. Journal of Applied Physics, 91, 9341-9345. https://doi.org/10.1063/1.1476071

[15] Lu, L., Sevonkaev, I., Kumar, A. and Goia, D.V. (2014) Strategies for Tailoring the Properties of Chemically Precipitated Metal Powders. Powder Technology, 261, 87-97. https://doi.org/10.1016/j.powtec.2014.04.015

[16] Wang, Z.L., Mohamed, M.B., Link, S. and El-Sayed, M.A. (1999) Crystallographic Facets and Shapes of Gold Nanorods of Different Aspect Ratios. Surface Science, 440, L809-L814. https://doi.org/10.1016/S0039-6028(99)00865-1

[17] Macko, J., Oriňaková, R., Oriňak, A., Koval, K., Kupková, M., Erdélyi, B., Kostecká, Z. and Smith, R.M. (2016) Hydrophobicity of Silver Surfaces with Microparticle Geometry. Applied Surface Science, 387, 1195-1201. https://doi.org/10.1016/j.apsusc.2016.07.054

[18] Macko, J., Oriňak, A., Oriňaková, R., Muhmann, C., Petruš, O., Harvanová, D., Vargová, J., Jendželovský, R., Radoňák, J., Fedoročko, P. and Arlinghaus, H.F. (2015) New Nanostructured Nickel-Polymer Nanohybrids with Improved Surface Hydrophobicity and Effect on the Living Cells Adhesion. Applied Surface Science, 355, 553-561. https://doi.org/10.1016/j.apsusc.2015.07.104

[19] Kynclová, H., Přibyl, J., Hrdý, R., Drbohlavová, J., Prášek, J. and Hubálek, J. (2014) Nanostructured Surface Effect of Electrode on Doxorubicin Determination. Applied 
Mechanics and Materials, 490-491, 262-266.

https://doi.org/10.4028/www.scientific.net/AMM.490-491.262

[20] Wen, Y.-N. and Zhang, J.-M. (2007) Surface Energy Calculation of the Fcc Metals by Using the MAEAM. Solid State Communications, 144, 163-167.

https://doi.org/10.1016/j.ssc.2007.07.012

[21] ACCU DYNE TEST (n.d.). https://www.accudynetest.com/liquid_tables.html

[22] Koenhen, D.M. and Smolders, C.A. (1975) The Determination of Solubility Parameters of Solvents and Polymers by. Journal of Applied Polymer Science, 19, 1163-1179. https://doi.org/10.1002/app.1975.070190423

[23] Carré, A. and Lacarrière, V. (2010) How Substrate Properties Control Cell Adhesion. A Physical-Chemical Approach. Journal of Adhesion Science and Technology, 24, 815-830. https://doi.org/10.1163/016942409X12598231567862

[24] Smith, M.K., Singh, V., Kalaitzidou, K. and Cola, B.A. (2015) Poly(3-Hexylthiophene) Nanotube Array Surfaces with Tunable Wetting and Contact Thermal Energy Transport. ACS Nano, 9, 1080-1088. https://doi.org/10.1021/nn5027406

[25] Sahoo, G.P., Bhui, D.K., Bar, H., Sarkar, P., Samanta, S., Pyne, S. and Misra, A. (2010) Synthesis and Characterization of Gold Nanoparticles Adsorbed in Methyl Cellulose Micro Fibrils. Journal of Molecular Liquids, 155, 91-95. https://doi.org/10.1016/j.molliq.2010.05.013

[26] Tran, R., Xu, Z., Radhakrishnan, B., Winston, D., Sun, W., Perrson, K.A. and Ong, S.P. (2016) Data Descriptor: Surface Energies of Elemental Crystals. Scientific Reports, 3, Article No. 160080. https://doi.org/10.1038/sdata.2016.80 